\title{
The Vron - a short-stay rehabilitation hostel
}

\author{
C. E. RoBson, Senior Registrar, Department of Psychiatry, Gloucester House, \\ Southmead Hospital, Bristol BS10 5NB
}

The development of hospital hostels was advocated by the DHSS in 1975 . These combined the clinical expertise and back-up of hospital resources with a domestic environment. The suggested level of provision was eight to ten places per 200,000 population in areas of average need and ten to 12 places in high need areas.

Short-stay rehabilitation hostels can be defined as units for the chronically mentally ill who are at risk of becoming new long-stay patients, in which the building is physically separate from the parent hospital, there is a daily programme of 'life skills' training and a limited length of stay.

The Vron is an eight bedded short-stay rehabilitation hostel opened in central Gloucester in 1985, serving a population of 530,000 . This paper describes the hostel and reviews the patients rehabilitated there between January 1985 and December 1991.

\section{The hostel}

\section{Suitable patients}

Patients referred for rehabilitation are assessed by the multidisciplinary rehabilitation team and are accepted for the Vron as requiring life skills training and having ability to move on to other placements within a maximum stay of 18 months.

\section{Staffing}

Each resident is reviewed on a weekly basis by a consultant rehabilitation psychiatrist, a senior registrar (since 1989), a registrar, a clinical psychologist, a community occupational therapist, and a psychiatric social worker, each with a sessional commitment of one session a week. Two community psychiatric nurses, a group homes and a supported lodgings officer provide input when necessary. Clinical responsibility for the residents rests with the consultant psychiatrist who keeps their psychiatric notes at the Vron. The residents are registered with a local general practitioner who attends to their physical needs.

The hostel is staffed 24 hours a day by one head of home, one deputy head, two staff nurses (all RMNs), two enrolled nurses (EN(M)), two full and two part-time nursing auxiliaries. Leave is covered by working overtime. Virtually the same staff have remained throughout the seven years, forming a well motivated team. They are not part of the main hospital staff pool, maximising continuity of care.

\section{Activities}

On admission to the Vron residents are given an introductory booklet explaining the general aims of their stay, the role of staff and their own obligations. Residents sign a statement of commitment to adhere to a basic daily timetable of tasks.

Orem's model of care is used to produce individual care programmes from which each resident has his or her own timetable. Specific deficits can be identified using nursing assessment forms and self-care questionnaires, before short, medium and longterm goals are agreed. Residents are encouraged to make use of social service day centres, industrial occupational therapy and the amenities of Gloucester, all of which are within walking distance. All residents attend daily community meetings to discuss the running of the hostel.

There are no domestic staff and residents are responsible for shopping for food, cooking for each other, washing, cleaning, doing the laundry and gardening, staff assisting as appropriate.

Medication is on a twice daily basis if possible. Residents self-medicate and the Medidos system has improved compliance.

\section{Findings}

The seven years from 1 January 1985 to 31 December 1991 were surveyed. There was a total of 81 patients, 43 males and 38 females, with an average of 12 admissions a year to the Vron. Ninety per cent were single, $9 \%$ divorced and $1 \%$ widowed. All were unemployed.

The average age at first consultation for their illness was 20 years for men (range 13 to 33 years, s.d. $=8$ years) and 25 years for women (range 7 to 56 years, s.d. $=10$ years); $54(67 \%$ had spent less than one year in hospital. Ten (12\%) had spent between one and five years in hospital. Seventeen $(21 \%)$ had spent longer than five years in hospital. Of these three $(4 \%)$ had spent between five and ten years, and $14(17 \%)$ between ten and 47 years. 
TABLE I

Diagnosis of residents admitted to the Vron

\begin{tabular}{lrcc}
\hline & Male & Female & Total (\%) \\
\hline Schizophrenia & 27 & 21 & $48(59 \%)$ \\
Affective psychosis & 10 & 13 & $23(28 \%)$ \\
Epileptic psychosis & 2 & 2 & $4(5 \%)$ \\
Herpes Encephalitis & 1 & - & $1(1 \%)$ \\
Obsessive compulsive neurosis & 3 & - & $3(4 \%)$ \\
Personality disorder & - & 2 & $2(3 \%)$ \\
\hline
\end{tabular}

TABLE II

Characteristics of residents admitted to the Vron

\begin{tabular}{|c|c|c|c|c|c|c|}
\hline \multirow[b]{2}{*}{ Year } & \multicolumn{2}{|c|}{$\begin{array}{c}\text { Age on } \\
\text { admission } \\
\text { to Vron (years) }\end{array}$} & \multicolumn{2}{|c|}{$\begin{array}{l}\text { Length of illness } \\
\text { on admission to } \\
\text { Vron (years) }\end{array}$} & \multicolumn{2}{|c|}{$\begin{array}{l}\text { Length of the } \\
\text { hospital admission } \\
\text { prior to admission } \\
\text { to Vron (years) }\end{array}$} \\
\hline & Male & Female & Male & Female & Male & Female \\
\hline 1985 & 53 & 57 & 28 & 26 & 13 & 14 \\
\hline 1986 & 41 & 49 & 18 & 23 & 10 & 9 \\
\hline 1987 & 33 & 41 & 15 & 23 & 0.33 & 5.33 \\
\hline 1988 & 23 & 50 & 6 & 29 & 0.17 & 10.42 \\
\hline 1989 & 29 & 30 & 10 & 11 & 0.25 & 1.67 \\
\hline 1990 & 30 & 40 & 8 & 16 & 0.33 & 0.17 \\
\hline 1991 & 34 & 54 & 8 & 23 & 0.33 & 1.50 \\
\hline$\overline{\mathbf{x}}$ & 35 & 49 & 13 & 22 & 3.75 & 7.75 \\
\hline Range & $18-68$ & $21-82$ & $2-46$ & $1-52$ & $0-45$ & $0-47$ \\
\hline S.D. & 18 & 18 & 12 & 22 & 11 & 12 \\
\hline
\end{tabular}

The average length of admission to the Vron was 6 months for both males and females (range 1 week to 22 months, s.d. $=5$ months). Only one man and one woman exceeded the target maximum length of admission of 18 months. This man (20) months was eventually discharged to a group home and the woman ( 22 months) to supported lodgings. Diagnosis did not significantly affect the length of the admission to the Vron. Patients were discharged to the following placements: own home: $9(11 \%)$; parents'/relatives' home: 13 (16\%); group home: 16 (20\%); supported lodgings: $23(28 \%)$; private residential home: $6(7 \%)$; long-stay rehabilitation hostel: $2(2.5 \%)$; psychiatric hospital: $7(9 \%)$; died in Vron (natural causes): $1(1.5 \%)$; still in Vron on 31 December 1991: $4(5 \%)$.

\section{Comment}

'New' long-stay patients are defined as people under 65 years old who have been in hospital for between one and five years, the 'old' long-stay having been resident for more than five years. In the absence of alternative provision new long-stay patients continue to accumulate in psychiatric hospitals and accounted for one third of the hospital population in a recent survey (Clifford et al, 1991).

Rehabilitation services have envisaged that rehabilitation could be completed within a prescribed period of time in half-way houses. However despite one to two years being believed to be the appropriate period in short-stay hostels, Hewett \& Ryan (1975) found that over half of the residents remained for more than two years even with a high level of recovery. They postulated residents were unwilling to exchange a high quality social and material environment for the more solitary existence otherwise available on their low incomes, in the absence of the lower intensity setting of group homes and supported lodgings.

Of the patients rehabilitated by the Vron, $93 \%$ had psychotic illness. They were commonly single, 
socially isolated, unemployed and with poor social skills. Numbers of men and women were approximately equal. Men tended to have a shorter length of illness, shorter hospital admissions and were younger on transfer to the Vron. In this study there was a higher proportion of younger male schizophrenic patients and older women with affective disorders as in the survey by Clifford et al (1991). Over the seven year period the average ages and lengths of hospital admissions decreased steadily, particularly for men as the old long-stay group were replaced by a group at an earlier stage of their hospital careers. In-patient numbers of Gloucestershire's large mental hospitals Coney Hill and Horton Road fell from 1,427 in 1960 to 406 when Horton Road closed in 1988. Coney Hill is scheduled for closure in 1994 and had 271 beds on 31 December 1991. On a census date of 26 September 1990 Coney Hill hospital had only a small residuum of 16 in-patients without dementia with a stay of greater than one year (Anstee, 1991).

The Vron's target maximum length of stay of 18 months was only exceeded twice and $80 \%$ of residents were able to leave directly for placements in the community. The majority of residents have so far avoided further hospital admissions. The remaining $20 \%$ have subsequently been placed outside hospital.

The government continues to encourage the development of hospital hostels as part of the community care policy in providing treatment for those with long term and severe mental health problems (Department of Health, 1992). The combination of a short-stay rehabilitation hostel utilising a domestic setting in the community, backed up by a well developed supported lodgings scheme and range of group homes with a further 46 placements in six long-stay rehabilitation hostels, has allowed many of Gloucestershire's more disabled psychiatric patients to avoid becoming first 'new' and then 'old' long-stay hospital patients.

\section{Acknowledgement}

I wish to thank Dr B. H. Anstee for his invaluable suggestions and encouragement.

\section{References}

ANSTEE, B. H. (1992) The residuum of a traditional psychiatric hospital. Psychiatric Bulletin, 15, 666-667.

Clifford, P. Charman, A. Weba, Y. \& Best, S. (1991) Planning for community care. Long stay populations of hospitals scheduled for rundown or closure. British Journal of Psychiatry, 158, 190-196.

Department OF Health (1992) Residential Needs for Severely Disabled Psychiatric Patients: the Case for Hospital Hostels. HMSO (ISBN 0-11-321451-0).

- \& Soctal Security (1975) Better Services for the Mentally Ill. Cmnd 6233. HMSO: London.

HewEtT, S. \& Ryan, P. (1975) Alternatives to living in psychiatric hospitals - a pilot study. British Journal of Hospital Medicine, 14, 65-70.

\section{Directory of staff training resources on the management of violence and aggression}

The Multi-Sectoral Interest Group on Violence and Aggression Management Training has received several enquiries on the availability of local staff training in dealing with violence to staff. We would like to produce a directory of local courses and training packs (videos, workbooks etc.) which could be issued in response to enquiries. The directory could also be used by researchers wishing to contact those involved in training.
We would be pleased to hear about courses or training resources available anywhere in the UK. Any groups or individuals who wish to be included in the directory should contact Dr Cameron Stark, Department of Public Health, Ross House, Hawkhead Road, Paisley, PA2 7BN for a registration form. No fee is payable, and the directory will be made available at cost when it is completed. 